\title{
Male-Driven Evolution in Closely Related Species of the Mouse Genus Mus
}

\author{
Sara A. Sandstedt,“* Priscilla K. Tucker
}

Department of Ecology and Evolutionary Biology and Museum of Zoology, University of Michigan, Ann Arbor, MI 48109, USA

RE: J Mol Evol (2006) 61:138-144 - A typographical error appeared in the text of this article. On p. 140, midway down the left-hand column, where it reads:

and variance of $\mathrm{X}$ is $\mathrm{V}(\mathrm{X})=\mathrm{Y}(1-\mathrm{X}) /\left[\mathrm{L}(1-4 \mathrm{X} / 3)^{2}\right]$ with $\mathrm{L}$ equal to the length of the sequence. it should instead read:

and variance of $\mathrm{X}$ is $\mathrm{V}(\mathrm{X})=\mathrm{X}(1-\mathrm{X}) /\left[\mathrm{L}(1-4 \mathrm{X} / 3)^{2}\right]$ with $\mathrm{L}$ equal to the length of the sequence. In other words, in the published version the symbol $\mathrm{Y}$ should have appeared as an $\mathrm{X}$.

* Present address: Department of Epidemiology, University of Michigan, Ann Arbor, MI 48109.

Correspondence to: Sara A. Sandstedt; email: sandsted@umich.edu 